\title{
Aiming for safer patient care: development of a needs-based anesthesia return-to-work program after a non-remedial leave of absence
}

\section{Pour des soins plus sécuritaires pour les patients : élaboration d'un programme de retour au travail en anesthésie fondé sur les besoins après un congé non relié au travail}

\author{
Judy Marois, MD, FRCPC (1) - Alexander Shysh, MD, FRCPC • Jan M. Davies, MD, FRCPC
}

Received: 22 September 2020/Revised: 21 February 2021/Accepted: 7 April 2021/Published online: 20 May 2021

(C) The Author(s) 2021

\begin{abstract}
Purpose During anesthesiologists' careers, a leave of absence (LOA) is common. After prolonged leave, updating may be beneficial in reducing concerns about knowledge and skill decrements. Although formal return-to-work (RTW) courses and checklists assist UK practitioners, and Australia mandates a one-month RTW program for each year away from practice, no Canadian RTW programs exist. This project aimed to determine the needs of anesthesiologists for an RTW program.

Methods This quality improvement activity developed a needs analysis survey that was sent to all practicing anesthesiologists in Alberta. Respondents provided their opinions about the requirements necessary for an RTW program.

Results Seventy-three of 350 eligible participants (21\%) responded; one-third of respondents were female. Thirty-four respondents (47\%) had taken at least one LOA, with a median
\end{abstract}

Supplementary Information The online version contains supplementary material available at https://doi.org/10.1007/s12630021-02014-1.

J. Marois, MD, FRCPC ( $\square)$

Department of Anesthesiology, Perioperative and Pain Medicine, Cumming School of Medicine, University of Calgary, Foothills Medical Centre, Calgary, AB, Canada

e-mail: Judith.Marois@ucalgary.ca

Department of Anesthesia, Peter Lougheed Centre, 3500 - 26

Avenue N.E., Calgary, AB T1Y 6J4, Canada

A. Shysh, MD, FRCPC · J. M. Davies, MD, FRCPC

Department of Anesthesiology, Perioperative and Pain Medicine, Cumming School of Medicine, University of Calgary, Foothills Medical Centre, Calgary, AB, Canada [interquartile range] duration of 6 [3-12] months. Overall, respondents thought the duration of an LOA requiring formal RTW updating should be 12 [6-15] months, with a median updating period of 7 [5-20] days. Those who had previously taken an LOA thought updating should occur after a shorter absence (11 [6-12] vs 12 [6-24] months, $P=0.009)$ and be shorter (5 [3-12] vs 10 [5-26] days, $P=0.007)$. Comments indicated RTW updating should be flexible and individualized. Upgrades of computer systems and equipment plus specific skills retraining were identified.

Conclusions Leave of absences are common among anesthesiologists. Appropriate departmental support before, during, and after a gap in clinical practice could be provided by an RTW program to help endorse knowledge, skills, and confidence. Results identified the needs of Albertan anesthesiologists and provided initial guidance in the design of a user-centred RTW program.

\section{Résumé}

Objectif Beaucoup d'anesthésiologistes prennent des congés personnels pendant leur carrière. Après un congé prolongé, la mise à jour des compétences peut être bénéfique pour réduire les inquiétudes en matière de connaissances et de perte de compétences. Il existe des cours et des listes de contrôle officiels de retour au travail pour épauler les praticiens au Royaume-Uni, et l'Australie exige que les praticiens suivent un programme de retour au travail d'un mois pour chaque année sans pratique; cependant, il n'existe aucun programme canadien de retour au travail. L'objectif de ce projet était de déterminer les besoins des anesthésiologistes pour un programme de retour au travail. 
Méthode Cette activité d'amelioration de la qualité de l'acte a mis au point un sondage d'analyse des besoins qui a été envoyé à tous les anesthésiologistes en exercice en Alberta. Les répondants ont partagé leurs opinions sur les critères requis pour un programme de retour au travail.

Résultats Soixante-treize des 350 participants admissibles (21\%) ont répondu; un tiers des répondants étaient des femmes. Trente-quatre répondants (47\%) avait pris au moins un congé, avec une durée médiane [écart interquartile] de 6 [3-12] mois. Dans l'ensemble, les répondants étaient d'accord pour dire que la durée d'un congé nécessitant une mise à jour officielle pour le retour au travail devrait être de 12 mois [6-15], avec une période médiane de mise à jour de 7 [5-20] jours. Ceux qui avaient déjà pris un congé estimaient que la mise à jour devrait être organisée après une absence plus courte (11 [6-12] vs 12 [6-24] mois, $P=0,009)$ et être plus courte (5 [3-12] vs 10 [5-26] jours, $P=0,007)$. Selon les commentaires, la mise à jour de retour au travail devrait être flexible et individualisée. Des mises à niveau sur les systèmes informatiques et l'équipement ainsi qu'un recyclage spécifique des compétences ont été identifiés.

Conclusion Les congés sont fréquents chez les anesthésiologistes. Un soutien départemental adéquat avant, pendant et après un congé de la pratique clinique devrait être offert via un programme de retour au travail afin d'assister les cliniciens au niveau de leurs connaissances, de leurs compétences et de leur confiance. Nos résultats ont permis d'identifier les besoins des anesthésiologistes albertains et ont fourni des orientations initiales pour la conception d'un programme de retour au travail centré sur l'utilisateur.

Keywords return to work - competence - patient safety · program development

Returning to work after a leave of absence (LOA) is challenging in any occupation. Workplace changes occurring during one's absence lead to stress upon return. There may be new equipment or job locations, and the workplace culture may have shifted. A team's composition may differ with new management, staffing, or policies. These modifications can contribute to difficulty returning to work beyond ensuring that core knowledge and skills are adequate.

Many workplaces have protocols for employee reorientation, ranging from informal buddy shifts to structured lists of requirements to be met before working independently. In healthcare, there are structured reorientation processes for staff, such as nurses. ${ }^{1}$ In contrast, most Canadian physicians must rely on themselves for any reorientation after an LOA.

In medicine, retraining frequently refers to entering a new clinical practice area or expanding one's scope of practice by learning additional skills. More often the terms re-entry or return to work are used to represent a resumption of clinical practice after a significant break. ${ }^{2}$ For clarity, return to work (RTW) will be used here to refer to the physician returning from a non-remedial LOA, and "updating" will refer to achieving currency of knowledge and skills.

Anesthesiologists may take an LOA during their careers for personal or professional reasons (apart from remediation), such as medical recovery, sabbatical, parental, or study leave. Declines in physicians' skills during time away from practice have not been studied extensively, the evidence being limited and mixed because of the scant number of studies available. ${ }^{3}$ Progressive duration of time out of practice does lead to skills declining over six to 18 months, initially with a steeper decrement and then more gradually over time. ${ }^{3}$ Both skill retention and duration out of practice are key factors in a physician's successful RTW. ${ }^{4,5}$ Nevertheless, physicians may or may not be required to undergo an assessment of competence after a significant gap in clinical practice.

The time period triggering an assessment or updating varies between Canadian provinces and across countries, without consensus in the evidence or among regulators. Although updating is often recommended after a gap in practice of two years, this suggestion is based on two-year study periods rather than an indication that two years is a critical period after which a formal RTW assessment and possible retraining is required. ${ }^{1,6}$ In fact, some jurisdictions use three years as a cut-off, since fellowship training may take two years. ${ }^{3}$

International programs and regulatory requirements for RTW processes are summarized in Table 1. The Figure summarizes the Medical Board of Australia's RTW framework. These descriptions highlight the differing definitions of a "prolonged LOA" and the frameworks guiding RTW processes. Patient safety underlies some frameworks, which emphasize RTW plans that aim to return practitioners to appropriately supported practice, thereby ensuring safety of patients and practitioners alike. ${ }^{1,7}$

In contrast, Canada lacks such formal, structured RTW assistance. Despite established processes for longer LOAs, there remains a gap for temporary LOAs that are less than two to three years' duration, and no specific guidelines exist for a technical specialty such as anesthesia. Having ended an LOA, anesthesiologists most often simply go back to work. There may be no reorientation before providing anesthetic care in operating rooms new to the 
TABLE 1 Formal regulatory return to work requirements and refresher programs after non-remedial leaves of absence

\begin{tabular}{|c|c|c|c|}
\hline Location/regulator & $\begin{array}{l}\text { Duration of } \\
\text { "prolonged" } \\
\text { LOA }\end{array}$ & Formal RTW process & $\begin{array}{l}\text { General resources } \\
\text { Anesthesia-specific resources }\end{array}$ \\
\hline $\mathrm{USA}^{2,16-20}$ & $1-5$ years & Variable & $\begin{array}{l}\text { Managing your career re-entering clinical } \\
\text { practice } \\
\text { Few, small reports, challenge to access }\end{array}$ \\
\hline $\begin{array}{l}\text { American Society of } \\
\text { Anesthesiologists }^{21,22}\end{array}$ & Not specified & & $\begin{array}{l}\text { Anesthesiologist Re-Entry Program } \\
\text { Directory }\end{array}$ \\
\hline Medical Board of Australia, Figure ${ }^{7}$ & 1 year & $\begin{array}{l}\text { Equivalent of } 1 \text { year's continuing } \\
\text { professional development activities } \\
+ \\
\text { Plan of "professional development and } \\
\text { re-entry to practice" if LOA }>3 \\
\quad \text { years }\end{array}$ & - \\
\hline Medical Council of New Zealand ${ }^{23}$ & 3 years & $\begin{array}{l}\text { A period of supervised practice } \\
+ \text { A return to practice plan } \\
+ \text { Regular reporting to Council }\end{array}$ & - \\
\hline $\begin{array}{l}\text { Australian and New Zealand College } \\
\text { of Anaesthetists }{ }^{24,25}\end{array}$ & 12 months & $\begin{array}{l}\text { 1-month RTW program per } 12 \text { months } \\
\text { away from practice }\end{array}$ & $\begin{array}{l}\text { CRASH course-Critical care, Resuscitation } \\
\text { and Airway Skills in High Fidelity } \\
\text { Simulation }\end{array}$ \\
\hline $\begin{array}{l}\text { UK Academy of Medical Royal } \\
\text { Colleges, UK General Medical } \\
\text { Council }\end{array}$ & $>3$ months & & $\begin{array}{l}\text { Guidance/support (mentors, seminars, } \\
\text { simulation, etc.) } \\
\text { "Keep in touch" days within National Health } \\
\text { Service (NHS) contracts } \\
\text { Locally based RTW simulation courses/ } \\
\text { refresher seminars }\end{array}$ \\
\hline Royal College of Anaesthetists ${ }^{27,28}$ & $\begin{array}{l}\text { Any LOA } \\
1 \text { year } \\
3 \text { years }\end{array}$ & $\begin{array}{l}\text { Pre-/post-LOA to help the practitioner } \\
\text { develop plans for return to work } \\
\text { Structured approach } \\
\text { A "significant period" of supervision } \\
\text { and assessment }\end{array}$ & $\begin{array}{l}\text { GASagain } \\
\text { Essential Knowledge Update - Core Topic } \\
\text { Days }\end{array}$ \\
\hline Canada Provincial Medical Colleges & $2-3$ years & $\begin{array}{l}\text { Case-by-case process of assessment/ } \\
\text { updating }\end{array}$ & \\
\hline Canadian Anesthesiologists' Society ${ }^{29}$ & Not specified & & $\begin{array}{l}\text { Recommend supporting a returning } \\
\text { colleagues' re-education or rehabilitation }\end{array}$ \\
\hline
\end{tabular}

LOA = leave of absence; RTW = return to work.

practitioner, while using new equipment, and when providing anesthetic care for novel surgical procedures, with surgeons and nurses whom they have not previously met.

Consequently, perceived decrements in confidence, knowledge and skills, workplace changes, and no reorientation may all contribute to significant stress and distraction for the returning anesthesiologist, potentially affecting safe patient care. Although previously recognized and addressed in other countries (see Table 1), the combination of a predominantly public healthcare system, varying provincial licensing requirements and differing physician employment structures merge uniquely in Canada. Non-Canadian RTW supports, courses, and reference documents, while useful, may not be entirely applicable to the Canadian context. Also, these existing resources may not be based on the actual needs of practicing anesthesiologists. Thus, we seek to address this gap in anesthesia care using a proactive approach: evaluating the needs of practicing anesthesiologists to develop a user-centred Canadian RTW program.

\section{Methods}

The aim of this quality improvement (QI) initiative was to use a needs analysis survey to determine the RTW desires of a cohort of practicing Canadian anesthesiologists. 
Quality improvement methodology recognizes that a needs analysis can help improve the quality of decisions about programs or policies under development. The purpose of the survey was to establish user-defined guidelines as to the duration of an LOA that could trigger a period of updating plus identify the preferred length, structure, and content of such an updating program. This QI activity would then guide the subsequent development of a practical RTW updating program. As a QI activity, this project was deemed exempted from review by the Conjoint Health Research Ethics Board, University of Calgary.

We created the survey based on the components of various RTW programs identified in the literature. We pretested the survey with a local sample of anesthesiologists to ensure proper question formatting and item inclusion. Before distribution, a human factors review was completed to improve readability and usability. The final survey version was distributed by email to a convenience sampling frame of all practicing (non-locum) anesthesiologists in Alberta between November 2018 and January 2019 (using an Alberta Medical Association [AMA] database, with permission). Advance notice was emailed by the anesthesia representative of the AMA. In a cover letter, participants were notified of the survey rationale and reassured of anonymity. Participants indicated consent by participating. One follow-up email reminder was sent. The survey instrument (see eAppendix, Electronic Supplementary Material [ESM]) included 33 items for all respondents, plus 26 questions for those who indicated previously completing an LOA (requesting additional detail of their LOA and RTW preparations). The survey was distributed using Qualtrics software (Version 11 of Qualtrics; copyright (C) 2018 Qualtrics, Provo, UT, USA). ${ }^{9}$ Responses were analyzed using the Statistical Package for the Social Sciences (IBM SPSS Statistics for Windows, Version 25; IBM Corp., Armonk, NY, USA). Descriptive statistics were analyzed using the Chi square test, frequencies were compared using the $\mathrm{F}$ test, non-parametric data were analyzed with the KruskalWallis $\mathrm{H}$ test, and differences in means were analyzed using the Student's $t$ test.

\section{Results}

The overall survey response rate was $21 \%$ (73/350). Table 2 describes respondents' demographics, level of training, and practice patterns. Two-thirds of respondents were male, but significantly more females had taken an LOA. Sixty-one respondents (84\%) worked in urban centres and 46 (63\%) were in later career stages. Thirtyfour study respondents (47\%) had taken an LOA, frequently within the first five years of practice (50\%).
Family/personal and medical/health were the most common reasons for taking an LOA (Table 3). The median [interquartile range] duration of an LOA was 6 [3-12] months. Twenty-one anesthesiologists (66\%) returned to the same type of anesthesia practice. Otherwise, changes in practice upon RTW included fellowship training, new career directions, splitting or reducing call or practice, and moving between tertiary/community settings.

Overall, respondents commented that the median duration of an LOA before requiring formal RTW updating should be 12 [6-15] months with a suggested median updating period of 7 [5-20] days (Table 4). Respondents who had previously taken an LOA (compared with those who had not) thought that an RTW program should occur after a shorter absence from work (11 [6-12] vs 12 [6-24] months; $P=0.009$ ) and be shorter (5 [3-12] vs 10 [5-26] days; $P=0.007$ ). These significant differences could indicate that the experience of taking an LOA yields a more nuanced opinion, compared with those respondents who were merely imagining a potential scenario (Table 4).

Furthermore, this survey benefitted from allowing those who had previously taken LOAs to share their experiences. For those respondents with LOA experience, the impression of knowledge and skill depreciation varied. Seventeen respondents (43\%) did not feel their knowledge had lessened. In contrast, others felt that global and subspecialty knowledge declined by up to $50 \%$ (Table 5 ). One-third did not think that their skills had faded during their absence (Table 5). The other two-thirds felt that regional anesthesia, thoracic epidural, and global skills were the most common skills to decline, with a perceived decrement of $10-60 \%$.

Those with LOA experience identified a variety of preparative strategies when returning to work. During an LOA, making regular professional contact with colleagues, undertaking regular updates of knowledge, and participating in continuing medical education events were common, as were, reviewing resuscitation protocols and simulation upon RTW. Nevertheless, despite their attempts at preparation for RTW, $41 \%$ of participants experienced a lack of departmental support (eTable 1, ESM), highlighting the need for additional support mechanisms. For others, departmental assistance on return included easier room assignments or those with senior residents, no call for a certain time period, and peer support. Opinions about the importance of departmental RTW supports gave higher rankings for work accommodations and updates on new policies/equipment than for supervised practice or having an assigned mentor.

With regards to specific components in designing an RTW program, the LOA group felt the most important 
TABLE 2 Respondent characteristics

\begin{tabular}{|c|c|c|c|c|c|}
\hline & & $\begin{array}{l}\text { Total } \\
N=73 \\
n(\%)\end{array}$ & $\begin{array}{l}\text { Previous LOA } \\
N=34 \\
n(\%)\end{array}$ & $\begin{array}{l}\text { No LOA } \\
N=39 \\
n(\%)\end{array}$ & $P$ value \\
\hline \multirow[t]{2}{*}{ Sex } & Female & $23(32 \%)$ & $19(56 \%)$ & $4(10 \%)$ & $<0.001 *$ \\
\hline & Male & $50(69 \%)$ & $15(44 \%)$ & $35(90 \%)$ & \\
\hline \multirow[t]{2}{*}{ Level of training } & FRCPC/equivalent & $35(48 \%)$ & $16(47 \%)$ & $19(49 \%)$ & $0.89 *$ \\
\hline & FRCPC with subspecialty & $38(52 \%)$ & $18(53 \%)$ & $20(51 \%)$ & \\
\hline \multirow[t]{3}{*}{ Practice location } & Calgary/Edmonton (Urban) & $61(84 \%)$ & $27(79 \%)$ & $34(87 \%)$ & $0.29 *$ \\
\hline & Rural & $10(14 \%)$ & $5(25 \%)$ & $5(13 \%)$ & \\
\hline & Urban/rural & $2(3 \%)$ & $2(6 \%)$ & $0(0 \%)$ & \\
\hline \multirow[t]{3}{*}{ Career stage } & Early $(0-5 y r)$ & $4(6 \%)$ & $2(6 \%)$ & $2(5 \%)$ & $0.39 *$ \\
\hline & Mid (5-15yr) & $23(32 \%)$ & $8(24 \%)$ & $15(39 \%)$ & \\
\hline & Late $(>15 y r)$ & $46(63 \%)$ & $24(71 \%)$ & $22(56 \%)$ & \\
\hline \multirow[t]{9}{*}{ Work pattern } & Work hours/week & & & & \\
\hline & Mean (SD) & $49(14)$ & $43(15)$ & $54(11)$ & $<0.001 \dagger$ \\
\hline & Median [IQR] & $50[40-60]$ & $41[32-51]$ & $50[50-60]$ & $0.03 t$ \\
\hline & Work weeks/year & & & & \\
\hline & Mean (SD) & $41(9)$ & $38(11)$ & $43(4)$ & $0.005 \dagger$ \\
\hline & Median [IQR] & $44[40-46]$ & $43[30-45]$ & 44 [40-46] & $0.68 t$ \\
\hline & Work FTE & & & & \\
\hline & Mean (SD) & $0.8(0.3)$ & $0.7(0.3)$ & $0.9(0.1)$ & $<0.001 \dagger$ \\
\hline & Median [IQR] & $0.9[0.8-1.0]$ & $0.8[0.5-0.9]$ & $1.0[0.8-1.0]$ & $<0.001 \ddagger$ \\
\hline
\end{tabular}

$\mathrm{FTE}=$ full time equivalent; IQR = interquartile range; $\mathrm{LOA}=$ leave of absence; $\mathrm{SD}=$ standard deviation .

*Chi square test; $† F$ test; $₫$ Kruskal-Wallis test.

TABLE 3 Primary reason for leave of absence

\begin{tabular}{lr}
\hline Reason & $n(\%)$ \\
\hline Family/personal & $16(47 \%)$ \\
Medical/health & $13(38 \%)$ \\
Education & $5(15 \%)$ \\
Recreational & $5(15 \%)$ \\
Practice overseas & $3(9 \%)$ \\
Sabbatical & $3(9 \%)$ \\
Practice in another area of medicine & $2(6 \%)$ \\
Other (business) & $1(3 \%)$ \\
Retirement & $1(3 \%)$
\end{tabular}

Percentages total $>100 \%$ because some respondents took more than one leave of absence.

would be reviewing the anesthesia workspace, resuscitation protocols, difficult airway management, and updates on trauma anesthesia (eTable 2, ESM). All respondents ranked a progressively increasing importance to RTW supports as the proposed LOA durations progressively lengthened from six months to two years (eTable 3, ESM).
Free-text comments indicated that an RTW updating program should be flexible and designed with variable content and duration according to each anesthesiologist's needs. Respondents also felt that, although longer LOAs would need longer periods of updating, the duration could be shortened for more experienced physicians. Previous experience, practice pattern and type, overtraining, career 
TABLE 4 Opinions on the duration of a leave of absence requiring updating and the period of updating required

\begin{tabular}{|c|c|c|c|c|}
\hline Duration (months) of LOA requiring update & $\begin{array}{l}\text { Total } \\
N=65\end{array}$ & $\begin{array}{l}\text { Previous LOA } \\
N=26\end{array}$ & $\begin{array}{l}\text { No LOA } \\
N=39\end{array}$ & $P$ value \\
\hline Mean (SD) & $12(8)$ & $9(5)$ & $14(8)$ & $0.004 \dagger$ \\
\hline Median [IQR] & $12[6-15]$ & $11[6-12]$ & $12[6-24]$ & $0.009 \$$ \\
\hline Period (days) of updating required & $N=62$ & $N=25$ & $N=37$ & \\
\hline Mean (SD) & $14(18)$ & $9(9)$ & $18(21)$ & $0.04 \dagger$ \\
\hline Median [IQR] & $7[5-20]$ & $5[3-12]$ & $10[5-26]$ & $0.007 \ddagger$ \\
\hline
\end{tabular}

$\mathrm{IQR}=$ interquartile range; $\mathrm{LOA}=$ leave of absence; $\mathrm{SD}=$ standard deviation.

$\dagger \mathrm{F}$ test; $\ddagger$ Kruskal-Wallis test. Number of respondents varies due to missing responses.

TABLE 5 Perceived knowledge and skills depreciation during a leave of absence

$\begin{array}{ll}\text { Percent of respondents acknowleging a decrement } & \text { Range of perceived } \\ \text { in this area } n(\%) & \text { decrement in this area }\end{array}$

\section{Knowledge}

No decrement

Global knowledge decrement

Guidelines and new techniques

Subspecialty anesthesia

Workspace

Equipment and medications

Confidence in skills

Skills

No decrement

Regional anesthesia

Global technical skills decrement

Thoracic epidural

Invasive monitors
$17(43 \%)$

$5(13 \%)$

$5(13 \%)$

$4(10 \%)$

$4(10 \%)$

$3(8 \%)$

$2(5 \%)$

$13(35 \%)$

$7(19 \%)$

$10-50 \%$

$6(16 \%)$

$10-50 \%$

$6(16 \%)$

$10-60 \%$

$5(14 \%)$
1-30\%

$10-50 \%$

$10-50 \%$

$20-100 \%$

$22-50 \%$

$20-40 \%$

Denominator is 40 for knowledge and 37 for skills because some respondents had more than one response.

stage and departmental support were important considerations in determining the duration of updating. Upgrades of various knowledge components, equipment, and routine matters, such as lockers, passwords, computer systems, etc., were also identified. Similarly, frequent reassessment during updating was considered essential, with formal updating to be neither burdensome nor a barrier, particularly with respect to major financial or time commitments.

Both LOA and no-LOA groups were unsure about existing LOA reporting and regulations for LOAs. That those previously taking an LOA were unaware to whom to report their LOA emphasizes the lack of current formalized processes and their need for further development.

\section{Discussion}

This survey ascertains the common occurrence of nonremedial LOAs among Albertan anesthesiologists. In fact, little is known about the prevalence of physician LOAs, but one study found that $12 \%$ of pediatricians in a US sample had experienced a period of clinical inactivity lasting $\geq 12$ months. ${ }^{10}$ At any given time in the UK, approximately $10 \%$ of postgraduate doctors are on an LOA. ${ }^{11}$ Our survey confirms that RTW programs may mitigate stress by addressing decrements in knowledge, skills and confidence that may lead to unanticipated, adverse patient events.

The survey also highlights key considerations when supporting physicians returning to practice: defining a "prolonged" leave, identifying the type and duration of beneficial updating, and creating constructive programs. 


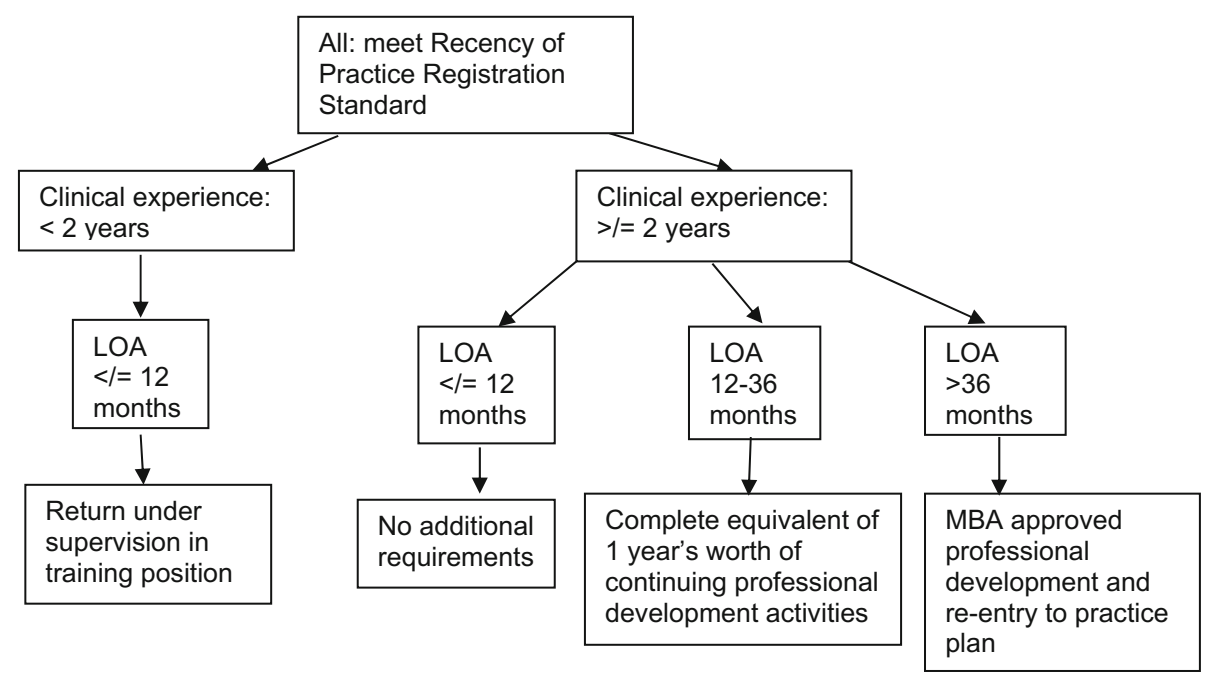

FIGURE Return to practice flowchart. Adapted from the Medical Board of Australia (MBA) fact sheet information on returning to practice, $2016 .^{7}$ LOA $=$ leave of absence.

Obtaining the detailed opinions of those who have experienced LOAs provides useful information to guide the development of such programs.

The UK and Australia have defined a "prolonged" LOA as three and 12 months absence from clinical practice, respectively (Table 1, Figure). ${ }^{1,7}$ In our survey, there were significant differences of opinion between respondents who had, or had not, taken an LOA. The LOA group thought that an RTW program should occur after a shorter absence from work (11 [6-12] vs 12 [6-24] months) and be shorter (5 [3-12] vs 10 [5-26] days). This difference in viewpoint highlights the valuable perspective of those who have actually lived the experience of an LOA, providing essential guidance in this area. Both groups ranked formal supports being of equivocal importance for LOAs less than one year, further confirming the assessment of nine to 12 months as the demarcation of a "prolonged" LOA. Adopting a Canadian definition would establish the foundation for moving toward consistent processes, expectations, and resources for those taking a temporary LOA.

While some respondents felt their knowledge and skills depreciated minimally over an LOA, others noted a more marked $(50 \%)$ decline, a significant decrement indeed. Thus, an RTW program may be essential for those individuals who feel their interim performance may have lessened considerably. Return to work supports were increasingly accessed upon returning to work rather than before, or during, an LOA. Departmental supports, especially work accommodations, were deemed important. When absent, this led to a challenging and negative RTW experience for the practitioner, suggesting a potential hazard to patients. More importantly, and of critical note, is the fact that a full $41 \%$ of the LOA group received no departmental support upon their return.

In terms of potential RTW program design, supervised practice and assigned mentors were ranked surprisingly as less important RTW supports, yet are components of the UK and Australia RTW processes. Instead, Canadian respondents valued review of resuscitation protocols, trauma anesthesia, and the anesthesia workspace. The spectrum of responses about the need for diverse RTW support mirrors the variability of decrements in knowledge and skills reported during an LOA. This reinforces the importance of considering individual needs in an RTW program, and that not everyone will want, require, or access this type of support. Nevertheless, this selective applicability does not excuse the fact that RTW programs are overlooked by most departments. Based on the international models, all departments should provide an RTW program as a basic resource, with reciprocal expectations that LOA returnees avail themselves of this and other resources.

Limitations to this study include its response rate and the lack of input from anesthesia trainees or those who had not returned to practice after an LOA. There could be a response bias of later-career physicians, whose LOA experience might not represent current medical culture, and whose lack of experience with simulation could have led to the surprisingly low importance placed on simulation for a proposed RTW program. There may also be an inherent response bias from those respondents who had previously taken an LOA, and from the significant number of male respondents in the no-LOA group. It is unclear if the LOA:no-LOA ratio is representative, as few data have been collected about LOA patterns among Canadian 
physicians. Nevertheless, the female:male ratio of respondents in this survey parallels national anesthesia demographics. ${ }^{12}$ Notable sex differences were found due to the significantly higher proportion of females in the LOA group. Such differences would also benefit from further study, considering the rising proportion of females entering medicine, the growing effect of maternity LOAs upon the physician workforce, and the high rate of women leaving medicine altogether. ${ }^{13,14}$

The recent development of RTW programs in various international jurisdictions underlines the need for Canada to follow. While this survey only included Albertan anesthesiologists and could thus have limited applicability elsewhere, it does represent an initial Canadian model for anesthesiologists elsewhere in the country. While the general format of other programs could be similar, any RTW program designed in Canada should also be individualized to meet the needs of the anesthesiologist cohort at each locale. Other localespecific designs could be constructed with a similar needs analysis, as this could improve the quality of new programs or policies.

The minimal research and evidence about "fading" of physicians' skills, LOAs, and clinical currency upon RTW (and therefore related patient care processes and outcomes) represent a gap requiring further study. The Canadian Medical Protective Association and Canadian provincial colleges vary in the information collected about physician LOAs; it is unclear if there are any links with adverse patient events or complaints. A

Strategies identified to mitigate fading of skills include keeping in touch with peers, remaining up-to-date, and overlearning, where the higher the learning proficiency before a leave, the higher the level of retention. ${ }^{4}$ Additional research is needed that considers individual circumstances, in particular, the role of overtraining during residency, global and specific skills fading, and skills retention in both novices and experts. ${ }^{3}$ Results of such research may allow more nuanced RTW requirements for senior practitioners, as was suggested by survey respondents.

Although this project introduces the concept of a structured RTW support for Canadian anesthesiologists who take temporary, non-remedial LOAs, it does not intend to replace any existing competency assessment processes. Rather, this RTW program proposes an optional, voluntarily accessed resource to provide updates to knowledge, skills, and confidence to assist Canadian anesthesiologists in regaining clinical currency before returning to work. The opportunity, exists to support the diverse needs of anesthesiologists and their patients.

\footnotetext{
A Personal communication from the Canadian Medical Protective Association, November 2018.
}

Indeed, Canada lags behind in creating guidance and resources for physicians returning to work. We are even further away from funding such initiatives. As a normal and expected part of the progression through training, the UK Department of Health committed $£ 10$ million of recurrent annual funding in 2016 to provide targeted support for doctors returning to training. ${ }^{11}$ While it may be challenging to prove a direct link to patient safety, stakeholder support for physician RTW has been achieved in the UK, given the potential effect on patient safety. ${ }^{11,15}$ There is, therefore, an opportunity for Canadian anesthesiologists to lead, through a forward-thinking approach incorporating QI and patient safety, in developing a Canadian anesthesia RTW program. Rather than waiting for an adverse event to trigger such a response, this pre-emptive approach would contribute to making Canadian anesthetic care safer.

\section{Conclusion}

Non-remedial LOAs are common among physicians. Accepting temporary LOAs as an expected, normal part of an anesthesiologist's career signals a shift in the traditional medical work model, one that can have positive effects on physician wellness, patient safety, and the medical culture overall. Undeniably, this shift will require changes in departmental support, administration processes, and workforce planning, all requiring data to promote and enable these physician RTW supports. This needs analysis survey yields baseline data required to drive this unique QI initiative. The Pilot RTW Program we have developed from this survey aims for safer patient care by ensuring that Canadian anesthesiologists are current, confident, and supported when returning to work after a temporary, non-remedial LOA.

Anesthesiologists who have taken temporary, nonremedial LOAs are valuable contributors to medicine. Both they and their patients deserve adequate RTW assistance to ensure optimal physician clinical currency and continued safe patient care. The best approach in supporting anesthesiologists returning to work remains unclear and no universal process will address the unique needs of each physician. Nevertheless, a framework of the process and an RTW program designed with and for Canadian anesthesiologists will be a step in the right direction.

Acknowledgement Thank you to Danielle Southern, biostatistician at W21C, Cumming School of Medicine, for assistance with statistical analysis.

Author contributions Judy Marois led the project and contributed to all aspects of this manuscript, including study conception and 
design; acquisition, analysis, and interpretation of data; and drafting the article. Alexander Shysh contributed to study conception and design; analysis and interpretation of data; and drafting the article. Jan M. Davies contributed to study design; interpretation of data; and helped write and revise the manuscript.

\section{Disclosures None.}

Funding statement This project was funded by the Safety \& Quality in Anesthesia Fellowship, Department of Anesthesiology, Perioperative and Pain Medicine, Cumming School of Medicine, University of Calgary.

Editorial responsibility This submission was handled by Dr. Gregory L. Bryson, former Deputy Editor-in-Chief, Canadian Journal of Anesthesia/Journal canadien d'anesthésie.

Open Access This article is licensed under a Creative Commons Attribution-NonCommercial 4.0 International License, which permits any non-commercial use, sharing, adaptation, distribution and reproduction in any medium or format, as long as you give appropriate credit to the original author(s) and the source, provide a link to the Creative Commons licence, and indicate if changes were made. The images or other third party material in this article are included in the article's Creative Commons licence, unless indicated otherwise in a credit line to the material. If material is not included in the article's Creative Commons licence and your intended use is not permitted by statutory regulation or exceeds the permitted use, you will need to obtain permission directly from the copyright holder. To view a copy of this licence, visit http://creativecommons.org/licenses/ by-nc/4.0/.

\section{References}

1. Academy of Medical Royal Colleges. Return to practice guidance 2017 revision. Academy of Medical Royal Colleges; 2017. Available from URL: https://www.aomrc.org.uk/wp-content/ uploads/2017/06/Return_to_Practice_guidance_2017_Revison_ 0617.pdf (accessed April 2021).

2. Katz JD, Burden A. Return to anesthestic practice after a prolonged absence. ASA Monit 2018; 82: 26-8.

3. General Medical Council. Skills fade: a review of the evidence that clinical and professional skills fade during time out of practice, and of how skills fade may be measured or remediated (Skills fade: a review of the evidence full report) 2014. Available from URL: https://www.gmc-uk.org/-/media/gmc-site-images/ about/skills-fade-literature-review-full-report.pdf?la=en\&hash= 8E0E20E07337E2344A5467F9B302C2D83CF2EBA5 (accessed April 2021).

4. General Medical Council. Skills fade literature review. 2014. Available from URL: https://www.gmc-uk.org/about/what-wedo-and-why/data-and-research/research-and-insight-archive/ skills-fade-literature-review (accessed April 2021).

5. Academy of Medical Royal Colleges. Return to Practice Working Group. Return To Practice Guidance Background Document. Academy of Medical Royal Colleges; 2012. Available from URL: http://aomrc.org.uk/wp-content/uploads/2016/06/Return_ to_practice_background_0412.pdf (accessed April 2021).

6. General Medical Council. Skills fade: a review of the evidence that clinical and professional skills fade during time out of practice, and of how skills fade may be measured or remediated
(Executive summary) 2014. Available from URL: https://www. gmc-uk.org/-/media/gmc-site-images/about/skills-fade-execu tive-summary.pdf?la=en\&hash=09D3F4BFB069F95F895DBF33 632A0F071BAA2DAF (accessed April 2021).

7. Medical Board of Australia. Fact sheet - Information on returning to practice. Melbourne; 2016: 1-4.

8. Alberta Innovates. ARECCI Ethics Screening Tool. Available from URL: http://www.aihealthsolutions.ca/arecci/screening/ 388056/7181b2da874f031ba4c72024547dacc2 (accessed April 2021).

9. Copyright (C) 2018 Qualtrics $^{X M}$. Qualtrics. Provo, Utah, USA: Qualtrics; Available from URL: https://www.qualtrics.com (accessed April 2021).

10. Freed GL, Dunham KM, Switalski KE. Clinical inactivity among pediatricians: prevalence and perspectives. Pediatrics 2009; 123: 605-10.

11. Health Education England. Supported Return to Training - 2017. Available from URL: https://www.hee.nhs.uk/sites/default/files/ documents/Supported Return to Training.pdf (accessed April 2021).

12. Royal College of Physicians and Surgeons of Canada. Royal College Medical Workforce Knowledgebase $@$. Data Dashboard. 2019. Available from URL: http://www.royalcollege.ca/rcsite/ health-policy/medical-workforce-knowledgebase-e (accessed April 2021).

13. Grace ES, Korinek EJ, Weitzel LB, Wentz DK. Physicians reentering clinical practice: Characteristics and clinical abilities. J Contin Educ Health Prof 2011; 31: 49-55.

14. Paturel A. Why women leave medicine. Association of American Medical Colleges; 2019. Available from URL: https://www. aamc.org/news-insights/why-women-leave-medicine (accessed April 2021).

15. Cohen D. Back to blame: the Bawa-Garba case and the patient safety agenda. BMJ 2017;359: j5534. DOI: https://doi.org/10. 1136/bmj.j5534.

16. American Academy of Pediatrics. Making Career Transitions. Reentering Clinical Practice. Available from URL: https://www. aap.org/en-us/professional-resources/practice-transformation/ managing-your-career/Pages/re-entering-clinical-practice.aspx (accessed April 2021).

17. The Center for Personalized Education for Physicians. Roadmap to Reentry. Available from URL: http://www.cpepdoc.org/wpcontent/uploads/2016/11/CPEP-Resource-The-Roadmap-toReentry.pdf (accessed April 2021).

18. Larson $C P$, Steadman $R H$. An advanced specialty training program in anesthesiology: a special educational fellowship designed to return community anesthesiologists to clinical practice. Anesth Analg 2006; 103: 126-30.

19. Joolukuntla A, Green MS, Hoffman CR. Success and challenge when returning to clinical practice: a case series in anesthesiologist reentry. American Society of Anesthesiologists; 2018: A2135 (abstract). Available from URL: http://www. asaabstracts.com/strands/asaabstracts/abstract.htm?year=2018 \&index $=12$ \&absnum=4472 (accessed April 2021).

20. Heyes ME, Schnitzen L, Starr DG, et al. Recertification and reentry to practice for nurse anesthetists: determining core competencies and evaluating performance via high-fidelity simulation technology. J Nurs Regul 2018; 8: P43-55.

21. American Society of Anesthesiologists (ASA). Statement on Personal Leave; 2018. Available from URL: https://www.asahq. org/standards-and-guidelines/statement-on-personal-leave (accessed April 2021).

22. American Society of Anesthesiologists (ASA). Anesthesiology Reentry Program. Available from: https://www.asahq.org/ education-and-career/career-resources/anesthesiology-re-entryprogram (accessed April 2021). 
23. Medical Council of New Zealand. Policy on applications for practising certificates where applicant has not practised medicine within the last 3 years - 2018. Available from URL: https://www. mcnz.org.nz/assets/Policies/Returning-to-practice-after-3-years. pdf (accessed April 2021).

24. Australian and New Zealand College of Anaesthetists (ANZCA). PS50 2017 Guideline on return to anaesthesia practice for anaesthetists. Available from URL: https://www.anzca.edu.au/ getattachment/01fc7ccc-1134-4120-8150-f69566e382fa/PS50Guideline-on-return-to-anaesthesia-practice-for-anaesthetists\# page $=($ accessed April 2021 $)$.

25. The Royal Melbourne Hospital. CRASH course - Critical care, Resuscitation and Airway Skills in High Fidelity Simulation. Available from URL URL: https://www.thermh.org.au/healthprofessionals/continuing-education/anaesthesia-and-painmanagement-courses/crash-course (accessed April 2021).

26. Randive $S$, Savic L. A structured return to work - who, when and why? Bulletin of The Royal College of Anaesthetists 2012; 76:
45-7. Available from URL: https://rcoa.ac.uk/sites/default/files/ documents/2020-07/Bulletin76.pdf (accessed April 2021).

27. Royal College of Anaesthetists. Returning to work after a period of absence. Available from URL: https://rcoa.ac.uk/documents/ returning-work-after-period-absence/introduction (accessed April 2021).

28. Royal College of Anaesthetists. Giving Anaesthesia Safely Again (GASagain). Available from URL: https://www.rcoa.ac.uk/ events/gasagain-giving-anaesthesia-safely-again-4 (accessed April 2021).

29. Canadian Anesthesiologists' Society. The Healthy Anesthesiologist. Available from URL: https://www.cas.ca/en/ practice-resources/the-healthy-anesthesiologist\# (accessed April 2021).

Publisher's Note Springer Nature remains neutral with regard to jurisdictional claims in published maps and institutional affiliations. 